\title{
A CROSS-SECTION PLOTTING PROGRAM (CSPP) FOR GRIDDED (MAP) DATA
}

By Richard B. Wells, Charles R. Faust and James W. Mercer

U.S. GEOLOGICAL SURVEY

Open-File Report 76-689

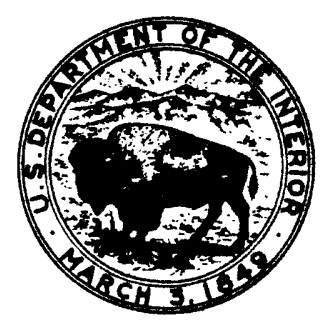




\section{U.S. DEPARTMENT OF THE INTERIOR \\ Thomas S. Kleppe, Secretary}

\section{GEOLOGICAL SURVEY}

V.E. McKelvey, Director

For additional information write to:

Chief Hydrologist

U.S. Geological Survey, WRD

431 National Center

Reston, Virginia 22092 


\section{CONTENTS}

Page

Abstract

Introduction

Program Description

Program Use

Data Input 10

Example 12

Program Listing 18

References 
FIGURES

Page

1. A rectangular grid showing the location of a section $A-A^{\prime}$

2. An example geologic cross-section corresponding to $A-A^{\prime}$ in

figure 1 -

3. An example of computed hydraulic-head profiles for various times along the section $A-A^{\prime}$ in figure 1

4. A portion of a typical grid showing the location of the interpolation point $\left(x^{\prime}, y^{\prime}\right)$ and the labeling of its neighboring grid intersections -

5. Areal finite-difference grid showing location of cross-section A-A'. Distance is in meters - 13

6. Structural map at the top of "Unit 3". Contour interval is 25 meters

7. Plot of geologic cross-section $A-A^{\prime}$ obtained from CSPP 17 


\section{TABLES}

\section{Page}

1. Listing of input data for example problem 
ABSTRACT

A FQRTRAN program that prepares the Calcomp plotter tape for drawing cross-sections from gridded map data is described and documented. The program accepts gridded data of the form $z(x, y)$, where $Z$ is the value at the grid intersection, $(x, y)$. Up to 10 sets of $Z(x, y)$ data for a given grid may be drawn on the same section. The positions of the end points of the cross-section are arbitrary. A bilinear interpolation scheme is used to obtain the $Z(x, y)$ values along the specified cross-section.

The program was designed to provide a visual aid for interpreting input and output data for two-dimensional (areal) finite-difference models used in aquifer analysis and geothermal reservoir simulation. The program should, however, be useful for drawing cross-sections of any multiple $Z(x, y)$ gridded data. The computer code is called CSPP standing for Cross-Section Plotting Program. 


\section{INTRODUCTION}

The purpose of this report is to describe and document a FQRTRAN computer program that draws cross-sections from gridded (map) data, using Calcomp plotter software. The program was designed to serve as a visual aid for evaluating input and output data of finite-difference models used in ground-water hydrology. The computer code is, however, general enough to be used for other applications. For example, the program could be used on gridded data supplied by the GPCP software package (California Computer Products, Inc., 1971)..$^{1 /}$

Some typical hydrological applications of the plotting program are given in the example section in this report. Commonly, in groundwater simulation applications, the aquifer and its confining beds are irregular. For such problems it is helpful to draw geologic crosssections based on the input data for the finite-difference grid (see figure 1). These cross-sections can be compared easily with available geologic sections to evaluate the accuracy of the input data (see figure 2). Output data can be evaluated in the same manner. For example, the computed values at specifiec times during a simualtion may be plotted on the same section for comparison with observed values (see figure 3 ).

II The use of brand names in this report are for identification purposes only and does not imply endorsement by the U.S. Geological Survey. 


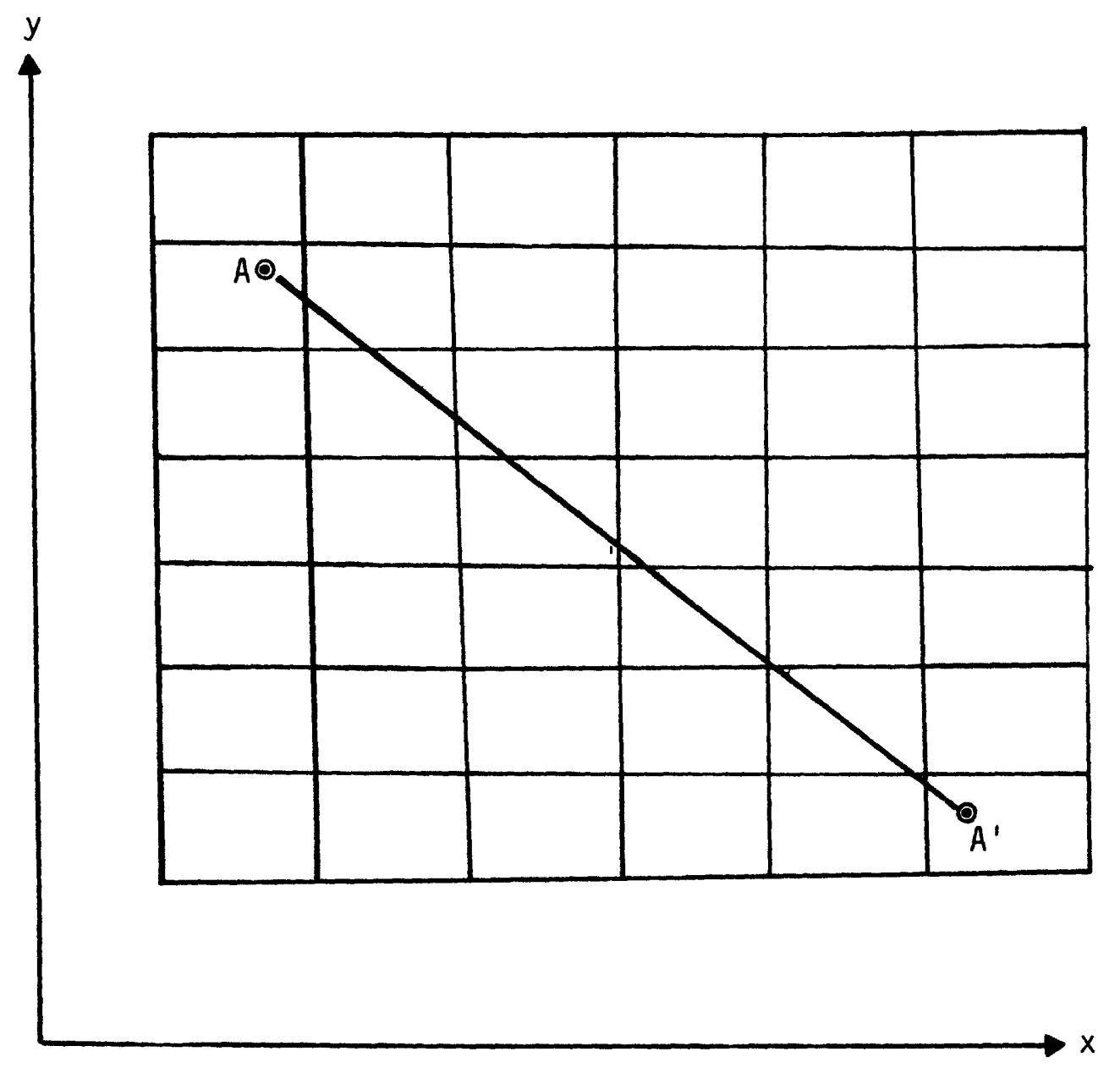

Figure 1. A rectangular grid showing the location of a section $A-A^{\prime}$. 


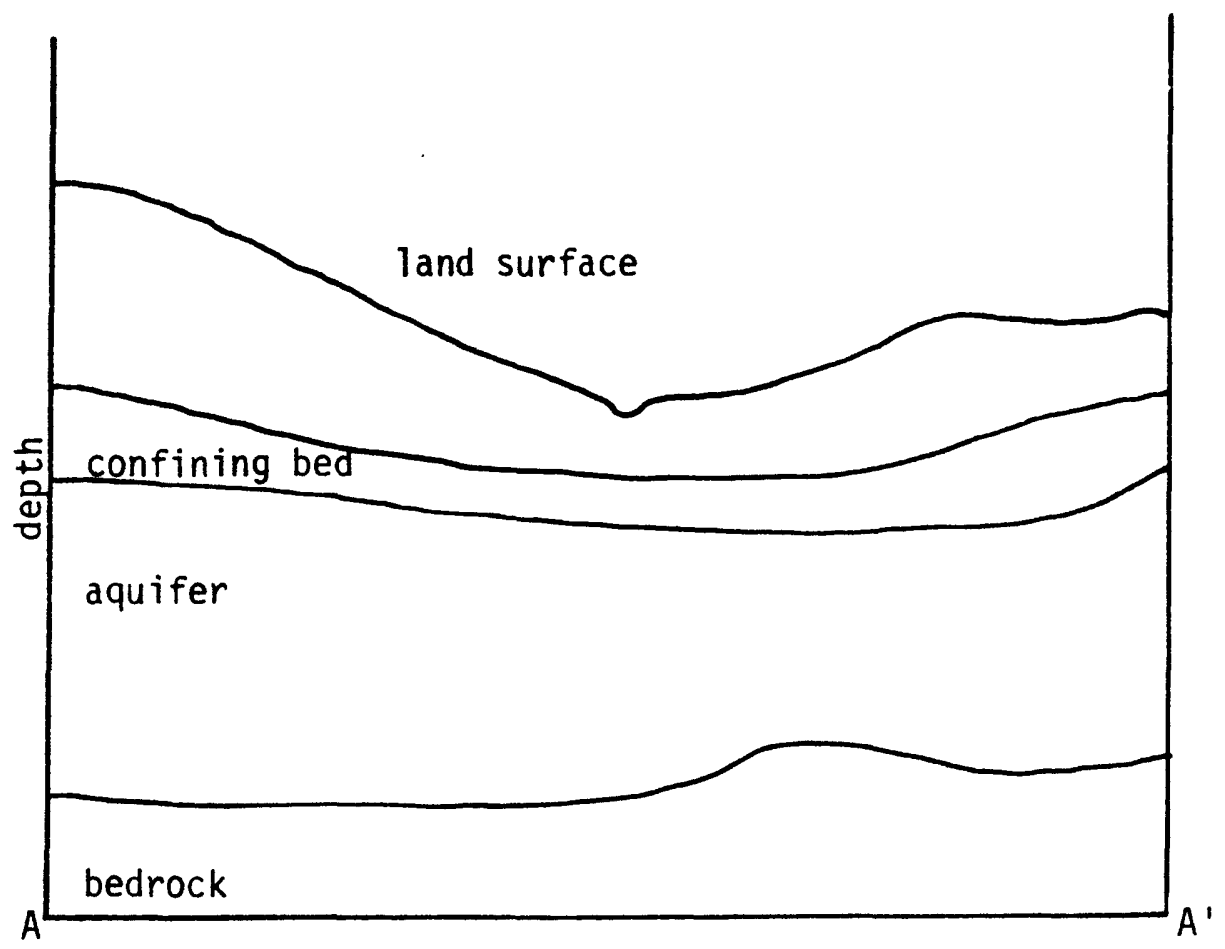

Figure 2. An example geologic cross-section corresponding to $A-A^{\prime}$ in figure 1 .

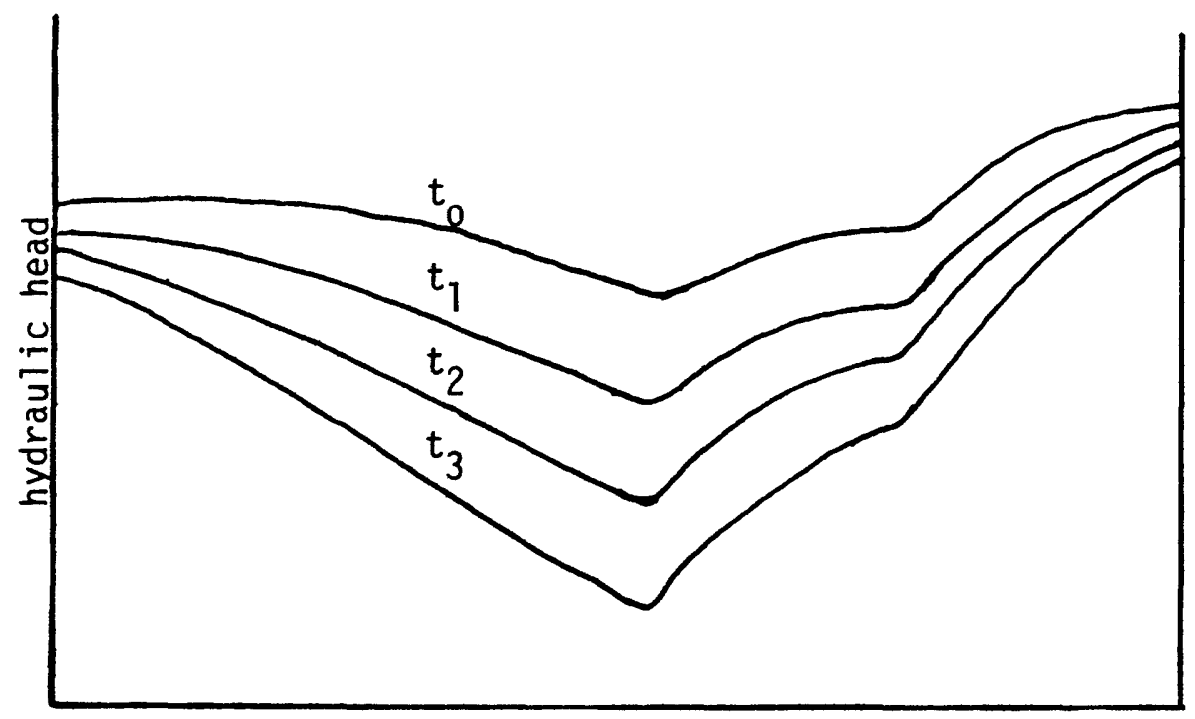

Figure 3. An example of computed hydraulic-head profiles for various times along the section $A-A^{\prime}$ in figure 1 . 
The object of the computer program is to communicate to the CALCOMP software the information necessary to draw the desired crosssection from given gridded data, $z(x, y)$. The user supplies the $x-$ and $y$-coordinates of the grid lines, the $z$-values for each grid intersection, the $x$ - and $y$-coordinates of the end points of the desired section, the number of intermediate interpolation points, and other data to control the scaling, size, and labeling of the plot. Up to 10 sets of $z$ - values may be plotted on the same cross-section. The computer program calculates the coordinates of equally spaced intermediate points (the number of which is supplied by the user) along the section, computes the $z$-values at the end points and intermediate points, and makes the necessary calls to the CALCOMP software. 
The numerical scheme that computes the values along the section is based on bilinedr interpolation for a rectangular grid. Figure 4 shows a portion of a rectangular grid and the position of an interpolation point $\left(x^{\prime}, y^{\prime}\right)$. The program must first locate the grid block that contains the point $\left(x^{\prime}, y^{\prime}\right)$. The value, $z\left(x^{\prime}, y^{\prime}\right)$ may then be calculated from

$$
z\left(x^{\prime}, y^{\prime}\right)=\sum_{k=1}^{4} z_{k} v_{k}
$$

where $k$ is the number of the surrounding grid points as shown in figure 4 , and $z_{k}$ is the corresponding value of $z(x, y)$ at the grid point. The interpolating function, $v_{k}$, is obtained from (Zienkiewicz, 1971)

$$
v_{k}=1 / 4\left(1+n n_{k}\right)\left(1+\xi \xi_{k}\right)
$$

where

$$
\begin{aligned}
& \xi=1-2\left(\frac{x_{i}-x}{x_{i}-x_{i-1}}\right) \\
& n=1-2\left(\frac{y_{i}-y}{y_{i}-y_{i-1}}\right) .
\end{aligned}
$$




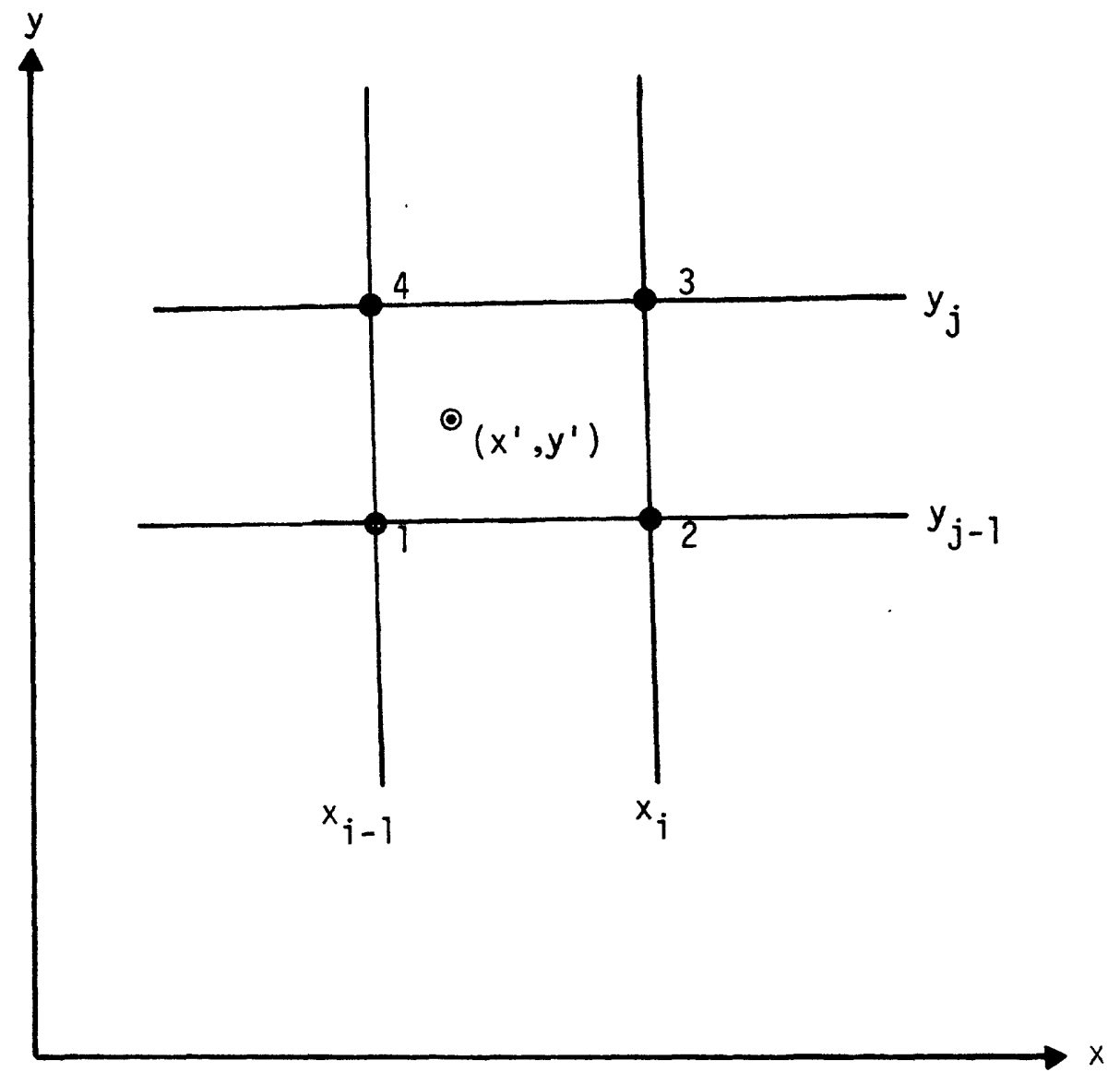

Figure 4. A portion of a typical grid showing the location of the interpolation point $\left(x^{\prime}, y^{\prime}\right)$ and the labeling of its neighboring grid intersections. 
PROGRAM USE

This program was designed to be applicable to a large variety of potential uses. The only input required is several parameters specifying dimensions, scaling, labeling of the cross-section plot, and the $X, Y$ and $Z(x, y)$ values (as many as ten sets of $Z(x, y)$ are permitted).

Another input parameter allows the user to specify the amount of interpolation to be done for each curve of the cross section. The user specifies the number of equally spaced points between endpoints $A$ and $A$ ' at which the program will compute the corresponding $Z(x, y)$ values by interpolation. The accuracy and smoothness of each curve depends on this parameter and it should be carefully chosen.

The following control cards are necessary to run this program: //JQB CARD

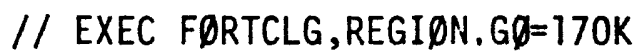

//FQRT.SYSIN DD *

DECK

//LKED.SYSLIB DD DSN=SYSI. CALCQMI . C936. PLOTTER,DISP=SHR

$/ / G Q . F T O 9 F 001$ DD SYSQUT $=(K,,<F O R M \#>) \quad\left[\begin{array}{l}\text { Prepares output for tape } \\ \text { retrieval }\end{array}\right]$ $/ / G D . S Y S I N \quad D D *$

\section{DATA}

$$
\text { // }
$$

These control cards are used in conjunction with a Data 100 Model 78 terminal and were provided to us by Steven P. Larson, WRD. For other terminals, the normal CALCOMP software and plot-tape must be used. 
The sample problem that follows used 170K bytes of core on the IBM 370/155. The core used will depend largely on the number of grid points. The program calls the following subprograms:

1) GETVAL (interpolates at intermediate points)

2) CALCOMP BASIC SOFTWARE PACKAGE (California Computer Products, Inc., 1969)

On a successful run the program will print the $x, y$ coordinates and the $Z(x, y)$ for each of the equally spaced interpolation points. All of the cross section points will be printed for each set of $z(x, y)$. If a point on the cross section lies outside the specified grid, an error message will be printed that includes the coordinates of the point, and the run will be terminated. 
DATA INPUT

$\begin{array}{lll}\text { COLUMNS FORMAT NAME } & \text { DESCRIPTION }\end{array}$

Card 1

$1-2$

$6-15$

$16-25$

$26-35$

$36-45$

46-50

$51-55$

$56-60$

$61-65$

$66-70$

Card 2

$1-10$

$11-20$

$21-40$

41-60

Gard 3

$1-30$

Card 4

$1-80$
I2

F10.0

F10.0

F10.0

F10.0

I5

I5

I5

I5

I5

F10.0

F10.0

5A4

5 A4

1013

20A4
ZS

No. of sets of data points to be input

$B E G(1)$ $x$-coordinate of the beginning cross section point

BEG(2) $y$-coordinate of the beginning cross section point

END(1) $x$-coordinate of the end cross section point

END(2) $y$-coordinate of the end cross section point

NX No. of $X$-values input

NY No. of $y$-values input

NUMPTS No. of points to be used for calculating the cross section

SETS No. of data sets to be plotted

NPEN No. of different colored pens to use (choice of 1,2 or 3 colors to al ternate when drawing cross section)

XUPIN Units/inch in the $x$-direction

YINCH If $>0$ No. of inches in the $y$-direction

If $\leq 0$ use XUPIN as scale for $y$-direction

XTITLE Label written on $x$-axis

YTITLE Label written on $y$-axis

SET(I) List (by order in which they are read in) of each data set that will be used in drawing the cross-section (up to 10)

TITLE Heading to appear at the top of the piot 
COLUMNS FORMAT NAME DESCRIPTION

NX/8 Cards

$1-80 \quad 8 \mathrm{~F} 10.0 \quad X(\mathrm{~J}) \quad x$-coordinates of grid points

NY/8 Cards

$1-80 \quad 8 F 10.0 \quad Y(K) \quad y$-coordinates of grid points

$Z S^{*} N{ }^{*} N Y / 8$ Cards

$1-80 \quad 8 F 10.0 \quad Z(I, J, K) \quad Z$-VALUES to be plotted

$I=$ No. Sets

$J=$ No. $x^{\prime} s$

$k=$ No. $y^{\prime} s$ 


\section{EXAMPLE}

This example demonstrates the use of the program in constructing geologic cross-sections from structural maps. Figure 5 shows a finitedifference grid and the location of the section $A-A^{\prime}$. Four sets of $z$-values were used in this example, and the input is shown in Table 1. Each data set is composed of elevation data on each of four geologic units; a structural map at the top of "Unit 3" (see figure 7) is shown in figure 6 . The elevations in figure 4 are in meters above mean sea level and were prepared for a finite-difference model using well data. The contours were plotted using the Calcomp GPCP program. Using the structural map in figure 6 and the other elevation data, the geologic cross-section $A-A^{\prime}$ in figure 7 was constructed. 


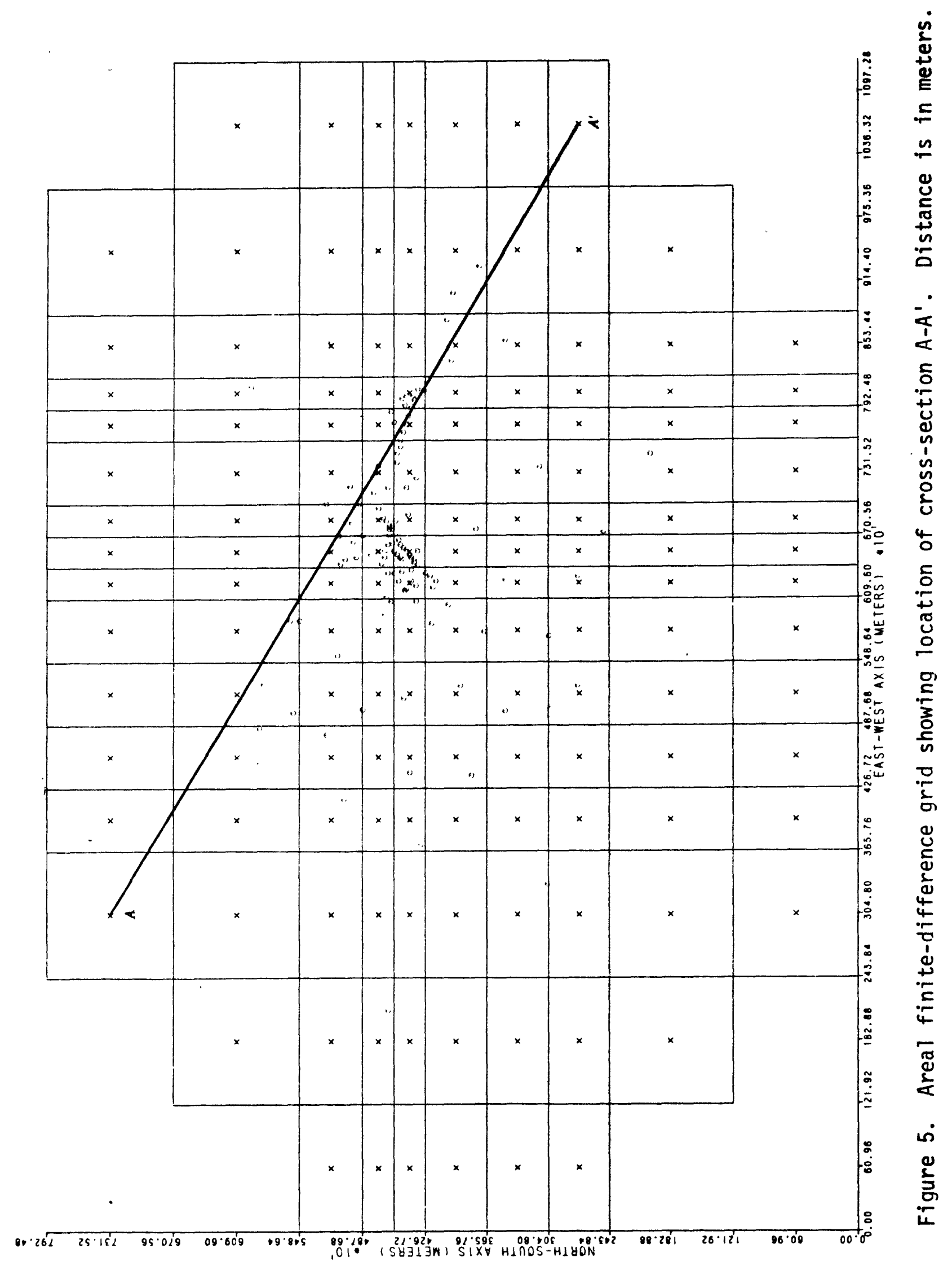




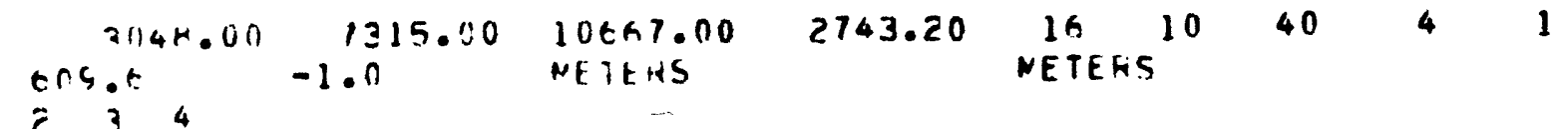

AOFIHWLST IC SUllHFOST CHCSS SFCTIOA

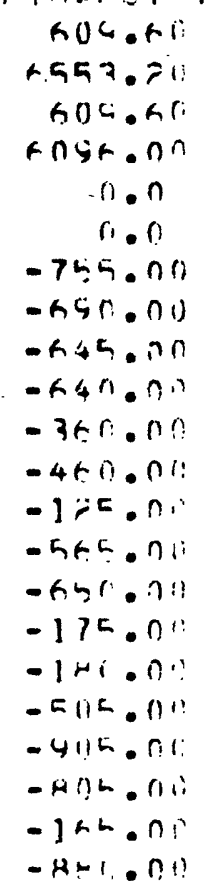

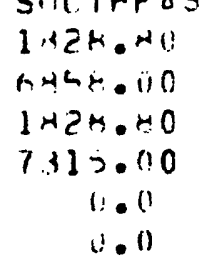

$? 04 \mathrm{R} .00$

3962.411

7315.00

7772.40

$457 ? .00$

$=74.7 .20$

3352.80

6077.21

5181.60

5791.70

४534.40 9444.40

$3962.4 n$

4419.60

4724.40

$6248 \cdot 4$
$\ln 66 P \cdot 0$

$-6.35 .00$

0.0

$-755.110$

-7in.110

$-4511.111$.

-nah. 110

- I5h. r.

- $3+11.110$

$-2=0.6$

$-224.116$.

$-6 \leq h .11 ?$

$-1+9.1: 1$

- Ifin.

- सh ali

$-\rightarrow 14.016$

- 71 i.

-ru. no

$-777.00$

- 10 Ja 00

-104 . nil

$r . n$

$n \cdot 1)$

2711.01

$340 . n 1$

उar.

34 (1. חII

in. 01

115.01

3ㄱ. กा:

355.01

रमे०ता

25i. 11

गfก. ก0

1s4. n!

1 25. 05

$2 \mathrm{C}^{2} .011$

2ं一c. 011

151.00

- c. 0 ?

$-11.00$

$$
\text { 11. } 0
$$

$r .0$

วसก.ก11

उसก.

$41^{2} .010$

$4>5 . \cap 5$

?5t. ก11

उAC. 011.

$375 . \cap \mathrm{C}$

$-1004.00$

$-1040.00$

$$
\text { ). }
$$

$$
\text { 1). } 1
$$

200.00

נ75. i)

375.110

inh.ro

3n. in

$1+6.00$

icu. 110

4is. 10

I 7 . 10

सेम.110

$2(-1) .00$

, 110.70

4h. 10

$1+11.00$

330.00

275.00

¿b.ro

$-10.00$

0.0

0.11

240.110

350.00

4111.00

$4 \therefore 0 . n n$

$195 . n n$

38i. 00

- 740.06

$-745.01$

$-60.00$

$-545.00$

$-645.00$

- ¿ब5. 110

- ¿lb.lir

- IPl. 110

- ti?n.ir.

- +5i5. ח1!

-14h. 01 !

- 300.110

- 7 .36. 119

$-4 \times 7.07$

- 40!.

.400 .00

-9 - 11.170

$-1040.119$

394.06

$$
0.1
$$

100.00

$>>11 . \hat{~}$

730.00

3th. nn

944 . त

175. $11 \mathrm{C}$

isn.0

270.00

$-64 h .0 n$

$-635.00$

$-655.00$

$-710.00$

$-645.00$

0.0

$-750.00$

-70n.00

$-515.00$

$-645.00$

$-305.00$

$-240.00$

$-230.011$

$-450.00$

-697.00

$-1.30 .00$

$-1+5.00$

-66's. 0

$-1005.00$

$-970.01$

$-70.00$

$-445.00$

$-1035.00$

385.00

395.00

0.0

150.00

235.00

361.00

3คก.00

ㄴ. 00

140.00

250.00

325.06

375.00

गPS. 110

?.11!. 110

115.

s1). (.C

1.5000

325.110

स(1). $n$

$-10.00$

4311.04

$$
0.0
$$

?3h. (1)

345.00

$380.0 n$

400.170

420.100

295.00

300.00

335.00

260.00

ว?5.00

125.00

20.00

60.00

320.00

145.00

$-5.00$

420.00

430.00

$$
0.0
$$

305.00

350.00

394.011

413.00

245.00

$-640.00$

$-6.35 .00$

$-700.00$

$-730.00$

$-540.00$

$-490.00$

$-645.00$

$-230.00$

- 265.00

$-235.00$

- 685.00

- K95.00

-65.00

$-550.00$

.955 .00

$-1035.00$

0.0

$-705.00$

$-1010.00$

375.00

390.00

395.00

75.00

170.00

370.09

375.00

385.00

160.00

260.00

265.00

340.00

$335.0 n$

325.00

150.00

70.00

$-5.00$

$$
0.0
$$

.325 .00

20.00

415.00

425.00

$43 n .00$

235.00

340.00

395.00

$-640.00$

$-510.00$

$-695.00$

$-640.00$

$-340.00$

$-645.00$

$-265.00$

$-255.00$

$-200.00$

$-585.00$

$-755.00$

$-70.00$

$-350.00$

$-860.00$

$-1035.00$

$-1040.00$

$-32 n .00$

$-910.00$

320.00

385.00

390.00

40.00

135.00

220.00

345.00

उ月川.0

125.00

255.00

250.00

265.00

215.00

320.00

200.00

115.00

$-5.00$

$-10.00$

330.00

120.00

385.00

420.00

425.00

200.00

$-745.00$

- O80.00

$-645.00$

$-640.0 n$

$-545.00$

$-650.00$

$-275.00$

$-500.00$

$-450.00$ 


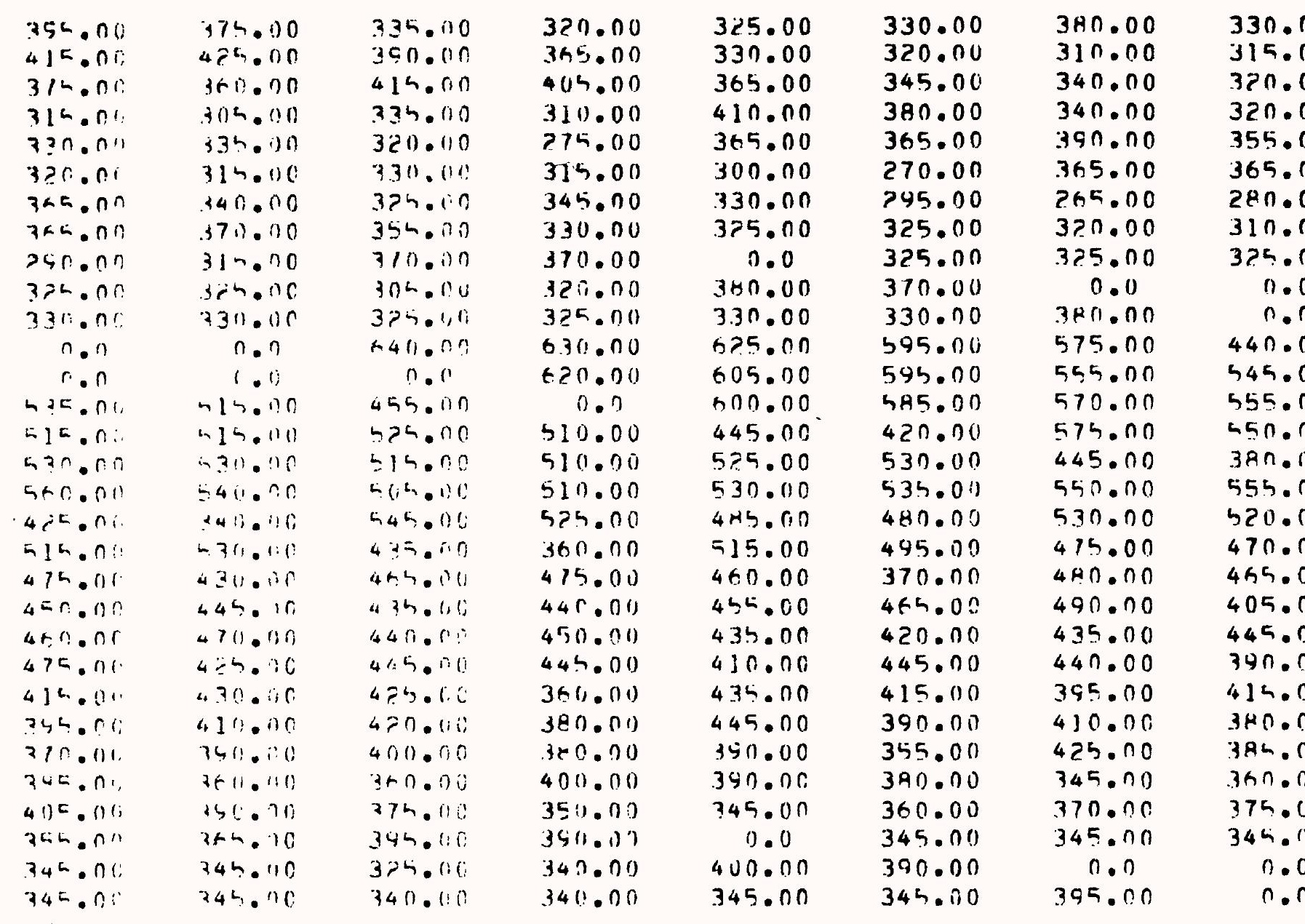

Table 1. Cont. 


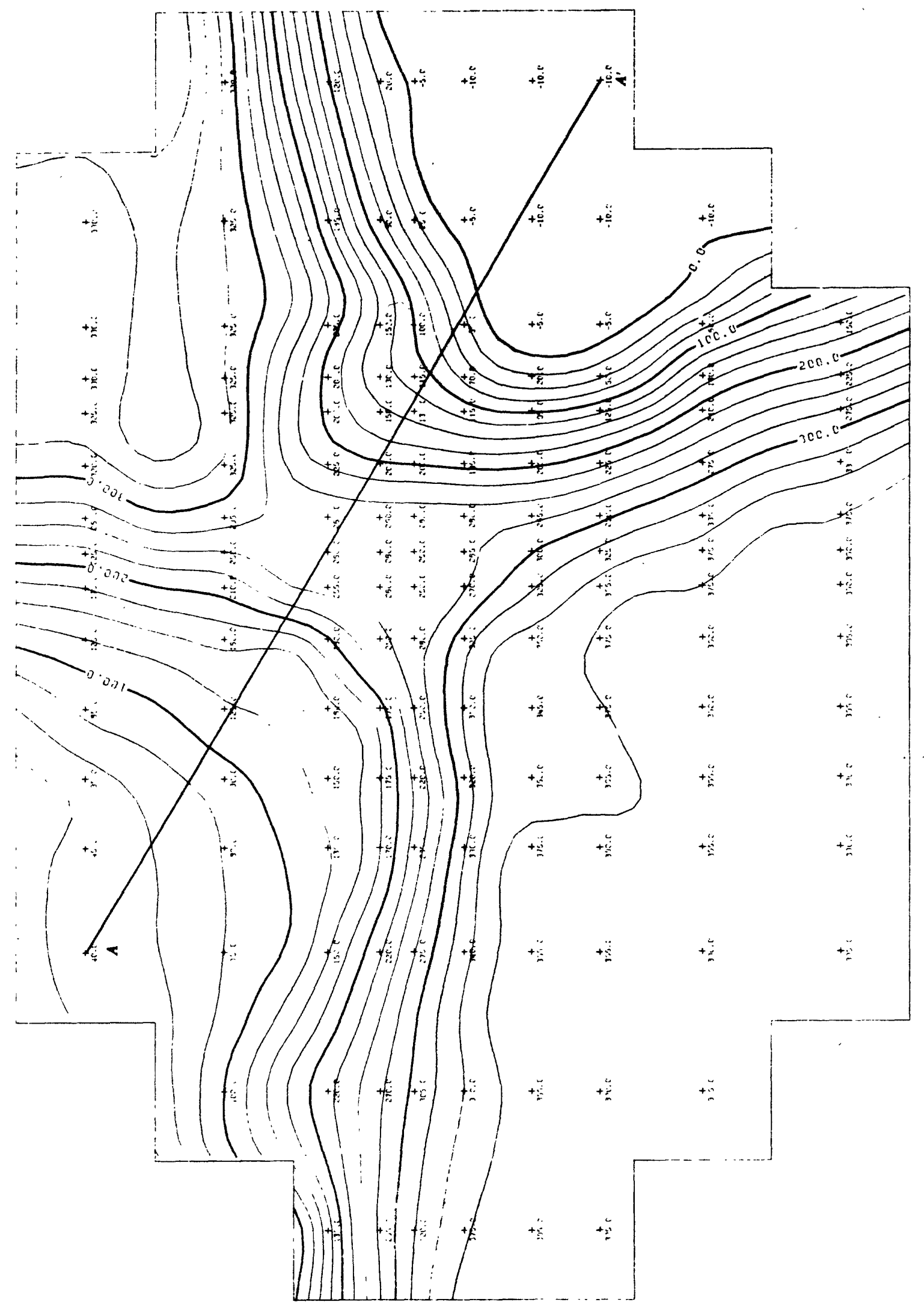

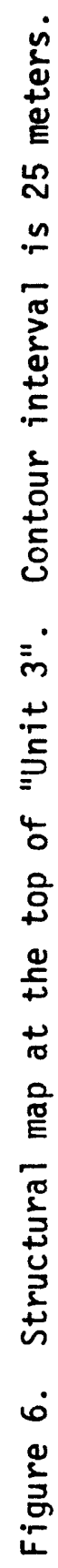




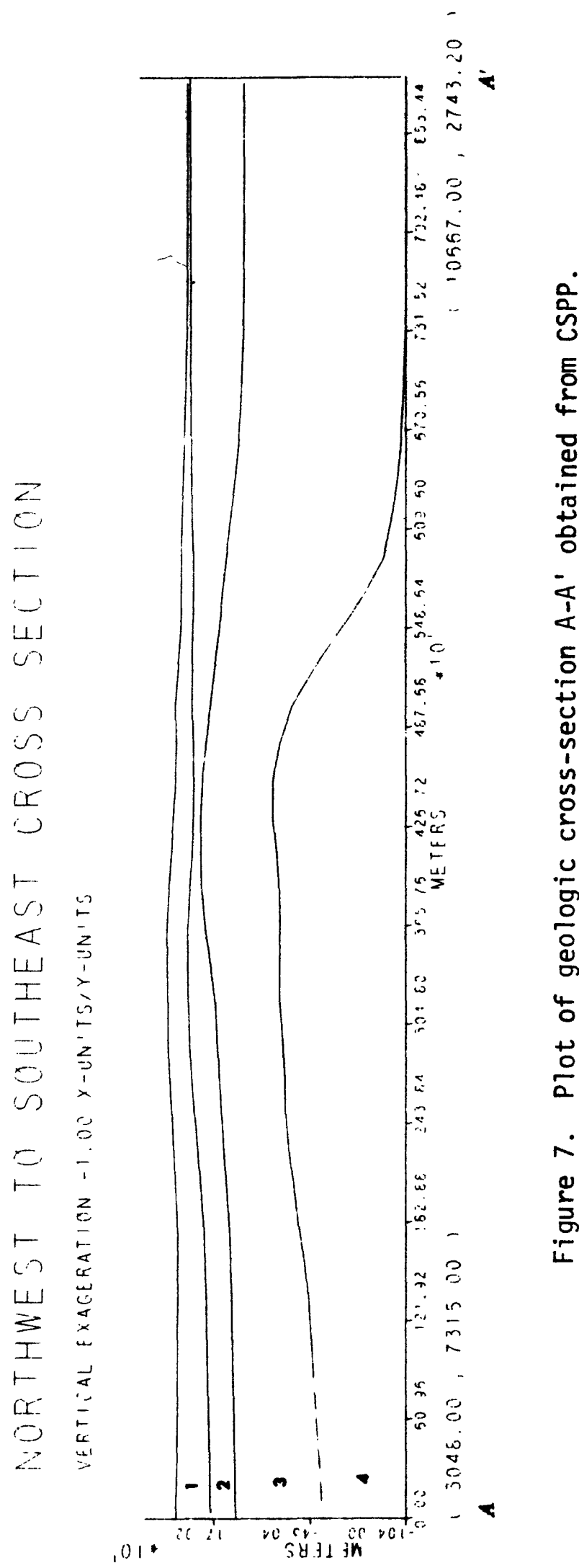




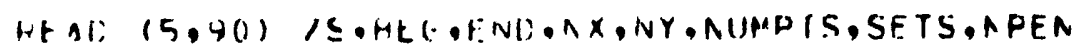

HF $(5,100)$ XLPIA.YIACH,XIITLF, YTTTI.E

HF AC . $(5 \cdot 11 \cup)$ (SF.T (I) $I=1 \cdot S E T S)$

HEAC $(5,120)$ TITLF

HFGL $(S, 1 ? 0) \quad(x(1), I=1, A x)$

HE Al: $(4,130)(Y(I), I=1, A r)$

IF (HEG(I).LT.X(I) .OH.HEG(I).GT.X(NX)) GO TC 70 


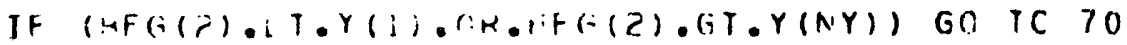

CES $b \in n$

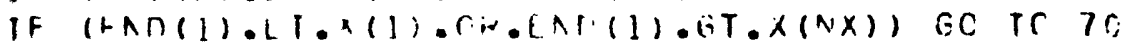

CRS 570

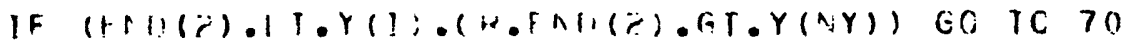

CHS $=80$

r: $10 x=1, \ldots$

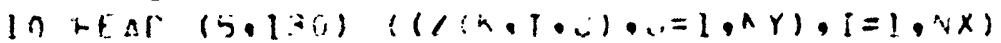

$r$
$r$
$r$

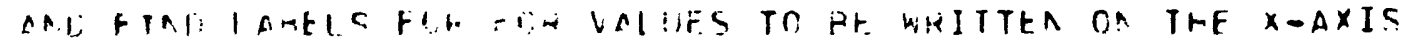

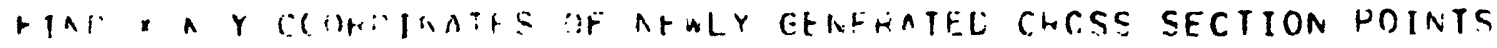

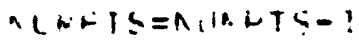

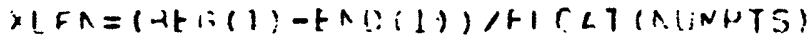

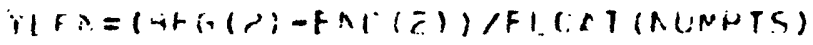

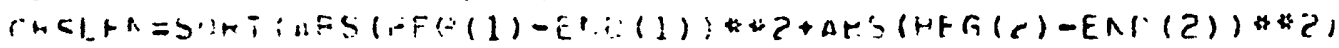

$\therefore x(1)=$ art (i) $(1$;

- $Y(1)=H+(: i)$ :

$=x \times(1)=0.6$.

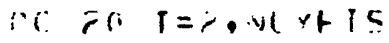

$\therefore r(1)=P Y(1-1)-Y L+A$

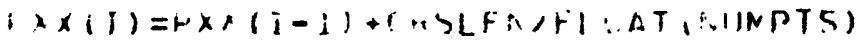

- $1: x(1)=0 \times(1-1)-x \mid+2$

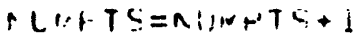

HX(AUND)

LY(NINR)

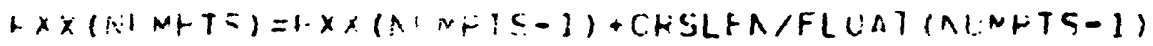

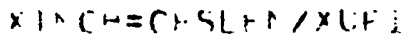

ce

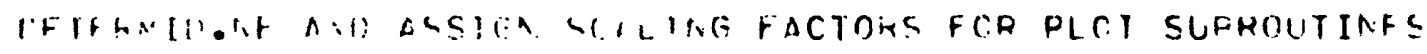

$i x \times(n, 1, m+1)+i)=r \times x(1)$

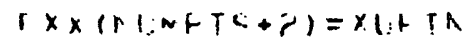

$\ln A x=Z 11 \cdot 1 \cdot 3)$

$\ln i n=2(1,1 \cdot 1)$

ir. $a^{\circ} k=1$, it is

ine $301=1, \ldots x$

$r$ z $30 \quad y=1, \cdots 4$

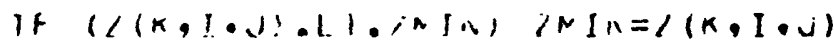

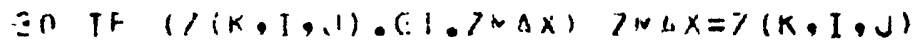

FYY $(M, 1 N F T S+1)=Z N I A$

I. FT $=(1 /, A X-1 / P T H: / Y I N C H$

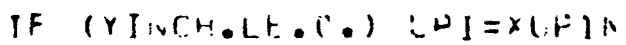

IF (YIN:CH.I.E OC.) YIAC.F=ITWAX-ZMINI/UD]

BYY $(\triangle L N+T S+Z)=L N$ !

FXA:= XIIr IA /1:+ I

$r$

$r$

c.

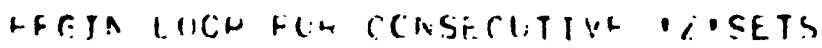

HFEIA I.OCH IC FIA! VAILFS A CROSS SECTION RCINTS

$n=1$

lic $t 1, \quad i=1$, it 15

I:C $40 x=1, n x$

$\operatorname{re} 40 I=1, \cdots Y$

$7 y(x \cdot I)=I(\operatorname{sit} I(n), k, I)$

40 CCNitinut

- hitir $(6.140)$ SeT(u)

nc $50 \quad 1=1$, numtis

CALL ETTVAL (i:X(I),NY(I),X,Y,ZZ,NX,NY,VALLF)

En EYY $(1)=V \Delta L$ LIF
CRS 590

CRS $A O O$

CRS GIO

CRS ACO

CRS A $\Xi 0$

CRS 440

CRS GEN

CRS REO

CRS $A>0$

CRS $\&$ \& 0

CDS + $S O$

CHS 700

CPS 710

CHS 720

CUS 730

CP. 740

CHS $7 \leq 0$

CDS $I \in O$

C.AS $77 n$

CPS 780

CWS 750

CaS PCO

CQS HIO

CDS FET

CHS HIO

CRS $R 40$

CRS $H \leq n$

CDS RED

CRS RIO

CPS RPI

CDS HSO

CDS 900

CDS 910

CDS 9 Ẽ

CDS $9 \geq 0$

CHS 940

Cas 950

CQS $Q \in O$

CRS 910

CRS 9t 1

C.RS 9SO

CRSIOOO

CHSIOIO

CDSInẼ

CDS10?0

CRS1040

CRSIOSO

CRSIOFO

CRSI070

CRSI REO

CRSIOSO

CDS 1100

CRSIIID

CRSIIEO 


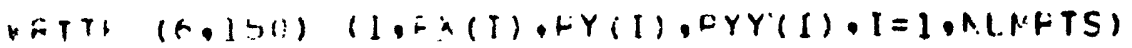

CRS 1130

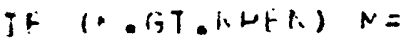

CnI Arnith(n)

$n=N+1$

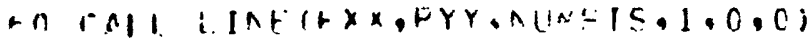

COS1140

CPS1150

CRS11 100

CRSIITn

CRSIIEO

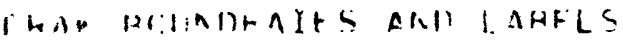

CRS11SD

CRSIPCD

$\because n ! A F P F A(1)$

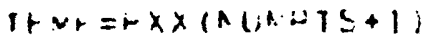

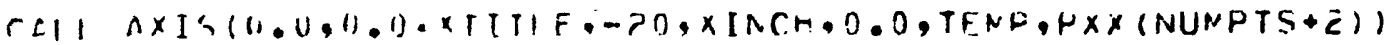

CRS1?10

CuS1 $2<0$

CRSIP3n

CPS1 240

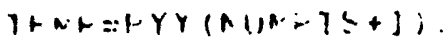

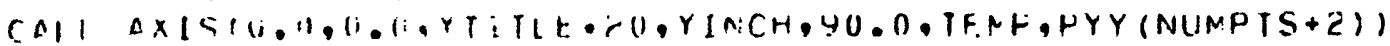

CRSI

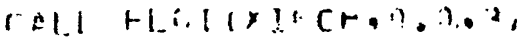

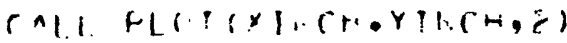

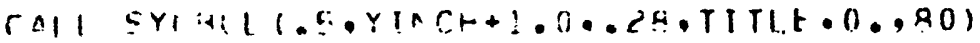

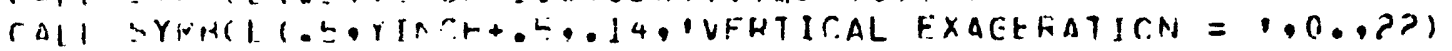

CRSI $1>0$

CRS1-70

CRSI 280

CRS1 250

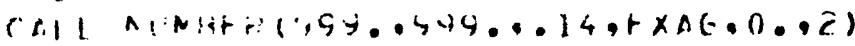

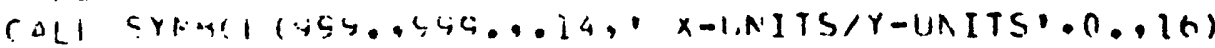

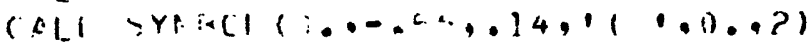

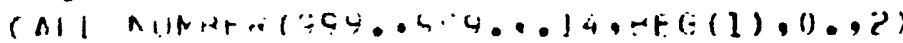

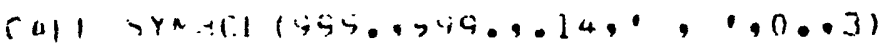

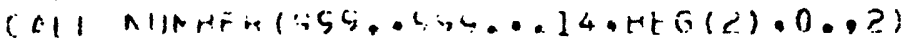

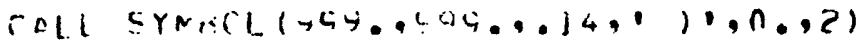

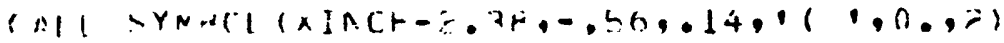

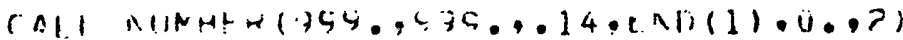

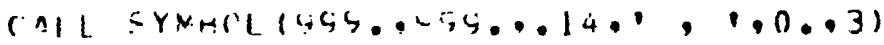

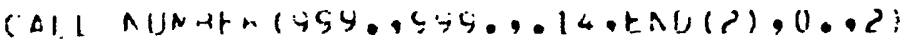

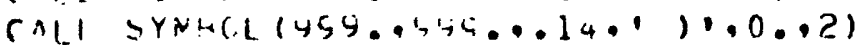

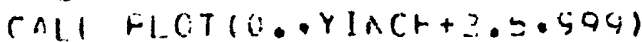

i $\mathrm{I}, \mathrm{H}(\mathrm{l}$

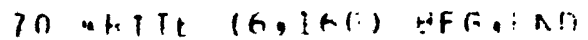

n CIrit

CRS130n

CDS131n

CRS13̈̈n

CRS13 30

$\operatorname{CoS} 1340$

CRS1350

CRSI 360

$\operatorname{Cos} 1370$

CRSI3En

CRS175n

CRC140?

CRS1410

CRS14=0

CRS14 3n

CRS1440

$\operatorname{CRS} 1450$

CRS1 $4+n$

CRS1470

$\operatorname{CDS1480}$

$\operatorname{cosil4} 40$

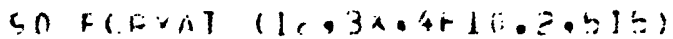

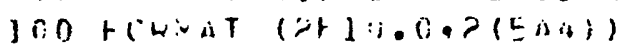

$110 \mathrm{fithL}$ (1) 13 )

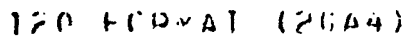

CRSI 1400

CQSI510

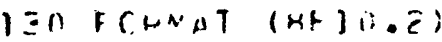

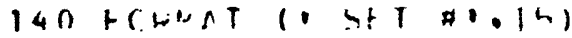

I

CRSI5Ẽ

CESI 530

$\cos 1540$

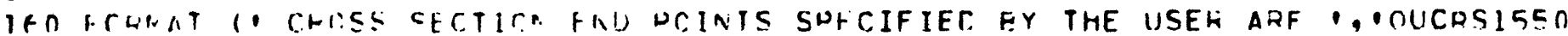

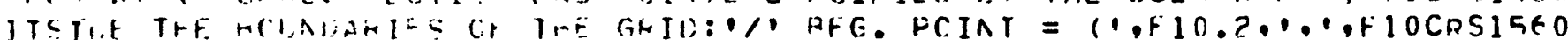

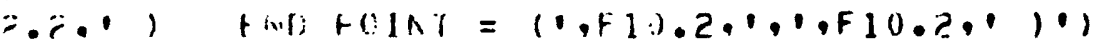

CRS1570 AN

CDS1580- 
$r$ IHIS SLRHOUTIIUE CALCLLATFS FY INTERPCLATION THE 2 VALUES AT THE CRCSSGFT 10

r. SFCTIOA FOIAT USIAG IHF FCLL GHIC POINTS FORMIAG A BOX AROLND THE FOIGFT EO

$r x_{t}-\quad x$-CCORETWATF OF POIAT AT WHICH VALLF IS TC BE CALCULATEC

$r$ YF- Y-COOFOITHAIE OF PGTAI AS WITH XP

$r x-$ SO ELEMEMI ANIAAY OF $X$-CUUHDINATES

C. Y- hO ELENEAT ALHAY OF Y-CCORDINATES

C. 7- $50 \times 50$ ELENEAT AIHAY CF L-VALIIES

C AX- \# GF $X-C$ OOHIINATFS DCTLALLY IISED IN THE AHRAY

$r$ AY- \# CiF Y-CUCHIINATES ACTUALLY USFL: IN THE AFRAY

C VALLR-THF, T-VALUF GF FUINT THAT IS RETURNEA TC CALLING ROLTINE

$c$

$r$

GLHHCTINE GH,TVAL (XP,YPOX,Y,Z,NX,NY,VALUE)

MINHNSICA $x(50), Y(50), Z(50,50)$

$F(A(A, \Delta), \Delta Z)=(Z \cdot \Delta A-(A)+\Delta ?)) /(\Delta Z-\Delta))$

$c^{2}$

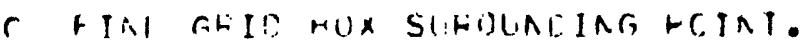

$r$ IF HCIAT IS MUT IN THE IEHIS THEN EAN THE PROGKAM

$r$

$\operatorname{lic} \ln l=1, \operatorname{ix} x$

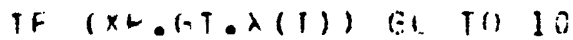

$i I=I$

r.r. in 50

11) rIATIAII

an $\operatorname{lor}$ zo $J=1$, ny

If $\left(Y H_{0}(\mathrm{~B}, \mathrm{Y}(\mathrm{U}))\right.$ (F) TO 30

$J_{c}=v$

Fer. TO 40

an CCATINISE

(AICLIOTE Z-VALAES FHIN Z-VALUES OF THE FOLR PCIATS FIUUND ABOVE.

4n $/ 1=1(11-1 \cdot J J-1)$

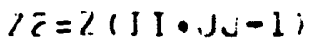

$73=\angle(11, \omega)$

$? 4=Z(1[-1, J J)$

$A M=E T \Delta(Y P, Y(J U-1), Y(J U))$

$F=F T \Delta(X F, X(I[-1) \cdot X(I I))$

$v l=.>h *(1 .-\Delta N) *(1,-F)$

$v_{c}=.>h+(1,-\Delta N) *(1 .+F)$

$V Z=. \partial t *(1,+\Delta B) *(1,+F)$

$V 4=.75 *(1 .+A R) \otimes(1,-E)$

$V A[1, t=V] * / 1+V E * 1 \bar{\varepsilon}+V 3 * 7 j+V 4 * \angle 4$

HETIHA

FAn

GFT 40

GFT 50

GFT $E 0$

GFT 70

GFT PO

GFT SO

GFT 100

GFT 110

GFT IEO

GFT 130

GFT 140

GFT $1 \leq 0$

GFT $1 \in 0$

GFT 170

GFT 180

GFT 150

GFT 200

GFT $>10$

GFT ZEO

GFT $>20$

GFT $>40$

GFT $\geqslant 50$

GFT ?EO

GFT ? 70

GET PEO

GFT $>S O$

GFT 300

GFT 310

GFT उẼ 0

GFT 33?

$G=T \quad 340$

fiET 350

GET $3 \in 0$

GET 370

GFT 380

GFT 3SO

GET 4 CO

GFT 410

GFT $4 E 0$

GFT 430

GFT 440

GET 4E0- 


\section{REFERENCES}

California Computer Products, Inc., 1971, GPCP A General Purpose Contouring Program: User's Manual.

California Computer Products, Inc., 1969, Programming Calcomp Pen Plotters.

Zienkiewicz, 0. C., 1971, The Finite Element Method in Engineering Science, London, McGraw-Hill Book Co., Inc., 521 p. 